\title{
Media User Types among Young Children and Social Displacement ${ }^{*}$
}

\author{
Tor Endestad, Jan Heim, Birgit Kaare, \\ Leila Torgersen \& Petter Bae Brandtzæg
}

\begin{abstract}
There is a lack of research on the role that new media play in the life of young children under the age of 13 years. Hence, the aim of the present study was to investigate the relationship between distinct media user types and social displacement among children under the age of 13. A sample of 1,117 Norwegian schoolchildren from the age of 7 to 12 years responded to a questionnaire about their computer game-playing habits and their use of computers, the Internet, mobile phones and television. The results indicate four specific user types reflecting children's various uses of new media: a) Advanced Users, b) Offline Gamers, c) Instrumental Users, and d) Low Users. Some indications of displacement were found between TV, reading and drawing and between new media usage and participation in organized sports activities. At the same time, clear indications support the "more is more" hypothesis, which predicts that active media users will be active children.
\end{abstract}

Keywords: user types, new media, social displacement, children

\section{Introduction}

There is a growing need to gain insight into the role that new media play in the life of young children (Roberts, Foehr and Rideout 2005; Wartella, O'Keefe and Scantlin 2000). A recent report from the EuKidsOnline project in Europe concluded that, in particular, there is a lack of research on young children under the age of 13 and their media usage (Staksrud, Livingstone and Haddon 2007). This age group is important to investigate, as younger and younger children are participating in an increasingly complex media landscape, which challenges our understanding of how new media influence childhood in earlier life stages.

The new media landscape has led several researchers to argue that new media have a greater impact on childhood than do traditional media (Tapscott 1998; Drotner 2001; Wright, Huston, Vandewater, Bickham, Scantlin and Kotler 2001; Heim, Brandtzæg, Endestad, Kaare and Torgersen 2007). For instance, heavy usage of new media has been associated with negative outcomes in relation to academic achievement, self-esteem and sociability (e.g., Roe and Mujis 1998; Heim et al. 2007). One of the hypotheses put forward is that time spent on new media technologies displaces the opportunity to engage in other activities. The time spent on various media becomes an issue, because the underlying reality is that individuals have a limited amount of time, which can be 
seen as a kind of social capital. If this capital is used on one activity, then less time is available for others (Gaddy 1986; Koolstra and van Der Voort 1996; Neuman 1991).

However, the interactive nature of new media technologies provides new opportunities for communication, information, entertainment and problem-solving (Anderson and Hanson 2009). Changes in media user habits appear to result from changes in user opportunities, access to different media technologies and social and cognitive developmental changes (Heim et al. 2007). As Roberts, Foehr and Rideout (2005) pointed out, there is a need to understand the increasingly complex patterns of use of media technologies in the emergent media-saturated society. One way of doing this is to identify typical user groups of new media, as suggested by Heim et al. (2007) and Johnsson-Smaragdi (2001), to better understand typical users and in what way media usage patterns are diversified in a more qualitative way.

According to Kraut, Kiesler, Mukhopadhyay, Scherlis and Patterson (1998), heavy use of the Internet and electronic games may lead to a decline in social interaction and psychological well-being, as indicated by lower scores on self-esteem. The most obvious explanation is a social displacement effect (Lee and Eddie 2002). The assumption of the social displacement effect is that time spent on media will displace other and more apparent activities, such as social interaction, that are essential to children's psychosocial development (Neuman 1991). However, the present study goes beyond existing research by not only looking at time spent with a particular type of media and analysing how various media activities or user types might lead to social displacement, but also by focusing on younger children's media use.

Thus, our main objective was to gain a better understanding of children's media usage in regard to different user types and how these are associated with social displacement. This was done by:

1. Characterizing children in terms of media user types in order to distinguish between significant preferences and patterns of media usage;

2. Identifying some of the key variables that explain various user types of new media, primarily in regard to how accessibility according to context of use influences children's patterns of media use; and

3. Determining whether and to what extent certain types of media use displace other social activities (the displacement hypothesis), such as reading books, magazines and playing with others.

New media are defined by Rice (1984) as communication technologies that enable or facilitate user-to-user interactivity in addition to interactivity between users and information. The main focus here will be on new media such as mobile phones, computers, game consoles and Internet usage, although television viewing is also central, as during the period of our study, almost all children spent the most time on this medium.

\section{User Typologies}

Media effect studies on children have primarily focused on time spent with media. Anderson and Hanson (2009) argued that researchers should only examine quantity as the sole measure of media input when it is of theoretical significance. They claimed that 
media content and form are often more important than time spent. It is the individual who chooses and creates meaning for the activities he or she engages in. And as stated by Krotz and Hasebrink (1998), it is possible to identify particular types of media usage. This allows analyses of the role media play for groups of children to be more precise than studies merely assessing frequency of use. Our approach to user types includes a combination of intensity in usage and activity preferences that take into account all the main activities involving several new media. Our definition of user types is therefore based on a holistic approach to media in general, and does not measure only one particular medium, as many studies have done thus far (see Roberts, Foehr and Rideout 2004).

Typically, demographic variables like gender or age have been linked to specific uses of new media technologies such as gaming, the Internet and mobile phones or to access to such technologies (Buckman and Funk 1996; Beentjes, Koolstra, Marseille and Van der Voort 2001; Wright, Huston, Vandewater, Bickham, Scantlin and R.M. Kotler et al. 2001). But as some authors have pointed out, as society becomes more and more media-saturated, the importance of demographic traits may have less explanatory power (e.g., Korgaonkar and Wolin 1999; Rogers 2003). We would therefore argue that there is a need for alternatives to the simple correlation between various demographic factors and amount of use. An alternative approach would be to look at the ways in which children differ in their use of media and to try to describe this use in terms of distinct media user typologies.

Some studies have already attempted to use such an approach. In a large study, Johnsson-Smaragdi (2001) used a cluster modelling technique to identify four main user profiles: Low Media Users, Traditional Media Users, Specialists and Screen Entertainment Fans. The data were collected from surveys conducted in 10 European countries for children aged 9-16. Eight variables covering various areas of use (reading, gaming, television viewing and computer usage) were included in the analysis. "Low Media Users" constituted the largest group in the study and were characterized by spending little time with media technologies. "Traditional Media Users" used media such as television and electronic games. "Specialists" were subdivided into four groups: television, book, PC and games specialists. "Screen Entertainment Fans" were subdivided into two subgroups: television and video, and television and games.

Roberts and Foehr (2004) found similar user types in a national random sample of U.S. children and adolescents 8 to 18 years of age. They based their analysis on six questions regarding total media exposure, number of different media used and accessibility. They found the following user types:

1. "Media Lites" (18\%) spent the least amount of time with media. They primarily spent time on television, music and printed media, and also had lower access to media and more restrictive media environments than the other types.

2. "Interactors" $(16 \%)$ embraced computers. They were less likely to have access to media in their bedroom, but more likely than other media user types to use a computer or read.

3. The "VidKids" (15\%) spent the most time with media, television or video accounting for nearly half their time. They had access to media in their bedrooms, but rarely had access to a computer at home. They mainly spent their time with entertainment media. 
4. Restricted (15\%) kids were living in the most controlled media environment with access to top technology, although they had strict rules for usage.

5. The "Indifferent" (18\%) kids had high access to media in both their homes and bedrooms, but spent less time with media than most youths.

6. "Enthusiasts" (19\%) were avid media users, reporting the most media exposure and living in the richest media environment. They were most likely to use almost every medium, and they spent more time with almost every medium than any of the other youngsters.

Both of the aforementioned studies measured the use of a range of old media technologies such as books, cartoons and music players in addition to new media like television, video, computers and game consoles. As such, they represent a good overall view in regard to the usage of different media types. However, because the focus in these studies was on media type and not so much on the activities performed with the media, it could be argued that they do not provide a complete picture of media usage. Another problem is that these two studies do not take into account the social implications of various user types.

An interesting question with regard to these user types is to what degree the media environment or the context of usage plays a role in the way children use media technologies. This is not necessarily only a question of accessibility, but is equally a matter of social, cultural and psychological accessibility or attractiveness (Johnson-Smaragdi 2001). Roberts et al. (2004) described a two-dimensional model of the media environment: the physical environment, which defines what kind of media young people can access in their homes, and the social environment, which includes family norms, policies and the general household orientation towards various media.

\section{Displacement}

The displacement hypothesis in its simplest form posits a symmetrical, zero-sum relationship between activities. According to this hypothesis, the more time spent with media, the less time children devote to other activities. This popular and in many ways obvious hypothesis implies that time spent doing one thing cannot be spent doing another. As Mutz, Roberts and Vuuren (1993) stated, this is hardly the case. You can listen to music, play a PC game and watch TV at the same time. Yet even if most youth are clever at multitasking, there are only 24 hours in a day and no one has unlimited attentional resources for parallel processing.

Social activities such as participating in social events, doing homework, reading and organized sports are perceived as important for children. Several theoretical mechanisms that might underlie possible social displacement have been suggested. An important factor may be whether an activity is perceived as important or marginal to the user as suggested in the "marginal activities hypothesis", because marginal activities can be sacrificed (Brown 1974). The "functional similarity" hypothesis (Hornik 1981) simply states that children would give up those activities that less effectively satisfy the same needs as their alternatives.

Another possibility is "the more, the more" hypothesis (Meyersohn 1968), which suggests that more active children engage in more new activities. The more interested they 
are in spending time doing sports, the more time they will devote to using media as well.

Even though there is no theoretical imperative stating that social displacement is the result of extensive media use, most of the empirical focus has been on negative effects and time use in general, not on different media user types. However, several studies have found negative effects of extensive media exposure. Subrahmanyam, Kraut, Greenfield and Gross (2000) summarized a portion of the literature raising the concern that an increase in the use of media technologies will be at the expense of other activities, putting the young at risk for obesity. Roberts et al. (2005) found that children who spent the most time with media were less content and tended to do worse in school than those who spent less time with media.

Another problem with most of the studies is that the questions about activities do not specify that the respondents should exclude compulsory physical activities at school. Because children have no control over mandatory activities, we would argue that any change or lack of change cannot be readily attributed to the use of media technologies. It is therefore possible that social displacement could occur in a less constrained arena than schoolwork.

\section{Method}

\section{Sample}

This study was based on a questionnaire survey that charted access to and use of new media among schoolchildren between 7 and 12 years of age $\left(2^{\text {nd }}, 5^{\text {th }}, 6^{\text {th }}\right.$ and $7^{\text {th }}$ grade $)$. The study took place in October and November 2002 in Norway, where access to and use of new media is high compared to other countries in Western Europe. At this point, most of the new media we know of today (in 2009) had just become accessible for children in Norway. A sample of 1,117 children from six different schools in the urban and suburban area of a city completed the questionnaire. The sample was stratified according to geographical and socioeconomic conditions in the city. Fifty-one percent of the sample were boys and $49 \%$ girls. Sixteen percent of the sample had a father or a mother from a country other than Norway. There was approximately the same number of children in all age groups, and the response rate was $90 \%$.

\section{Measures}

User types. We used 20 items measuring the frequency of different media-related tasks: (a) "Watch TV?", (b) "Play TV games?", (c) "Play Gameboy?", (d) "Play computer games on PC?", (e) "Play games on the Internet?", (f) "Play games with others on the Internet?", (g) "Download games from the Internet?", (h) "Internet surfing?", (i) "Write or read e-mail?", (j) "Download music from the Internet?”, (k) "Chat on the Internet?", (1) "Search for information for schoolwork on the Internet?", (m) "Do schoolwork on the PC?”, (n) "Draw or work with pictures on the PC?”, (o) "Work on homepage?”, (p) "Produce music on PC?", (q) "Make programs or demos?", (r) "Visit newsgroups?", (s) "Watch video/DVDs?", and (t) "TV chat". The responses were rated from 0 to 4 indicating: "never", "monthly", "weekly" and "almost every day".

Social and leisure activities. We used nine items measuring how much time was spent on different leisure activities in a typical week: (a) "Being with friends outdoors", (b) 
"Going to organized training", (c) "Meetings with scouts and the like", (d) "Playing ball outdoors", (e) "Being with friends at home", (f) "Spending time with family", (g) "Playing alone indoors", (h) "Reading books or cartoons", and (i) "Creating things, painting or drawing". Responses were rated from 0 to 7 .

Access to new media. We measured access to new media in the household using two questions: The first "Does your family have any of the following at home?" Yesor-no responses were given concerning the following new media: (a) "DVD/video", (b) "Gameboy", (c) "TV-games" (Playstation/Nintendo/Gamecube/X-box), (d) "PC/ computer" and (e) "Internet access". The second question "Do you have any of the following in your own room?" also required a yes-or-no response: (a) "TV", (b) "TVgames" (Playstation/Nintendo/Gamecube/X-box), (c) "DVD/video", (d) "PC/computer", and (e) "Internet access".

\section{Procedure}

The questionnaire was piloted with 38 children of the same age before it was used in the main study, and some modifications were made as a consequence (see Heim et al. 2007).

At each school, one teacher was appointed as the "liaison officer" to serve as the research team's link to the pupil, school and parents. This person was given advance information about the procedures used by the research team. Every pupil gave his or her written consent on the basis of both oral and written descriptions of the project formulated according to the standards prescribed by the Norwegian Data Inspectorate (NSD). According to these norms, written informed consent was also obtained from the pupils' parents. In accordance with a carefully defined standard procedure, the teacher monitored the pupils in the classroom during completion of the form. In each case, children were first instructed about the meaning of different scales in the questionnaire. All pupils completed the form at the same time in order to prevent them from influencing each other, and all the participants had one school period to complete the questionnaire. The teachers were instructed only to guide the children if they had problems understanding the questions. This methodology yielded a high response rate of $90 \%$.

The parents of the youngest children assisted in filling in the questionnaire because $2^{\text {nd }}$ graders have limited reading and writing skills. Filling out a form with the assistance of a parent is problematic on both ethical and scientific grounds. The answers may be biased and may represent a problem if questions are asked about issues that children do not want their parents to know about. This was judged to be a moderate risk, and getting answers from this age group was judged to be important, though the project budget would not allow individual interviews.

\section{Analysis}

The 20 items covering different types of new media usage were used to identify unique patterns of usage. A Two-Step Cluster model was used (SPSS 15 for Windows, SPSS inc. 1989-2006) because this method has been proven to deal well with large datasets, and provides flexibility regarding variable characteristics (Chiu, Fang, Chen, Wang and Jeris 2001). In order to identify the optimal number of segments, the Log-likelihood Distance measure and Schwarz's Bayesian Information Criterion (BIC) were used as described by Biernacki and Goavert (1999). Thirteen subjects who used the extreme score for all 20 
variables were excluded from the analysis. Table 1 shows the BIC values for each of the 15 possible solutions. The drop in BIC value and the degree of dissimilarity between the segments (distance measure) were used to identify the optimal classification of usage.

Table 1. BIC (Schwarz's Bayesian Criterion) Values for Cluster Solutions with Different Number of Segments (3 segments and one outlier group provided the optimal solution)

\begin{tabular}{lrrr} 
Clusters & $(\mathrm{BIC})$ & $\begin{array}{c}\text { BIC Change } \\
(\mathrm{a})\end{array}$ & $\begin{array}{c}\text { Ratio of BIC } \\
\text { Changes(b) }\end{array}$ \\
\hline 1 & 6137.292 & & \\
2 & 5695.643 & -441.649 & 1.000 \\
3 & 5486.189 & -209.453 & .474 \\
4 & 5432.516 & -53.673 & .122 \\
.. &.. &.. &.. \\
15 & 7274.930 & 216.601 & -.490 \\
\hline
\end{tabular}

\section{Results}

\section{User Types}

This led to a three segment model with one outlier group providing the maximum BIC change between cluster dissimilarity. Based on the typical usage pattern of each group, we labelled them Advanced Users, Offline Gamers and Instrumental and Sporadic Users. The Advanced Users represent the outlier group as a result of their being active in most of the tasks. Table 2 shows the number of subjects in each segment.

Table 2. Distribution of the Population in the Different User Groups

\begin{tabular}{|c|c|c|c|c|c|c|c|c|}
\hline & Total & $\%$ & $\begin{array}{c}\text { Boys } \\
\%\end{array}$ & $\begin{array}{c}\text { Girls } \\
\%\end{array}$ & $\begin{array}{l}\text { 2. grade } \\
\%\end{array}$ & $\begin{array}{l}\text { 5. grade } \\
\%\end{array}$ & $\begin{array}{l}\text { 6. grade } \\
\%\end{array}$ & $\begin{array}{l}\text { 7. grade } \\
\%\end{array}$ \\
\hline Advanced Users & 53 & 5 & 67 & 33 & 1 & 5 & 6 & 7 \\
\hline Offline Gamers & 277 & 25 & 76 & 24 & 39 & 26 & 23 & 12 \\
\hline Instrumental Users & 428 & 38 & 47 & 53 & 6 & 38 & 46 & 66 \\
\hline Sporadic Users & 352 & 31 & 31 & 69 & 54 & 31 & 25 & 15 \\
\hline
\end{tabular}

There is a significant effect by group for all the activity clusters: $\mathrm{PC}$ gaming $(\mathrm{F}(3,1106)$ $=87.977, \mathrm{p}<.001)$, TV gaming and Gameboy $(\mathrm{F}(3,1106)=303.963, \mathrm{p}<.001)$, Watching TV and video $(\mathrm{F}(3,1106)=41.377, \mathrm{p}<.001$, Newsgroups and TV chat $(\mathrm{F}(3,1106)$ $=133.420, \mathrm{p}<.001)$, tasks involving schoolwork on the $\mathrm{PC}$ and drawing $(\mathrm{F}(3,1106)=$ $82.578, \mathrm{p}<.001$, gaming $(\mathrm{F}(3,1106)=274.501, \mathrm{p}<.001)$, advanced tasks involving homepage construction and production of demos $(\mathrm{F}(3,1106)=283.011, \mathrm{p}<.001)$, and for more regular Internet tasks like surfing, downloading music and playing games over the Internet $(\mathrm{F}(3,1)=404.525, \mathrm{p}<.001)$.

Bonferroni-corrected post hoc tests were used to verify the uniqueness of the user groups. The criterion for the $\mathrm{p}$ value was set to $\mathrm{p}<.001$. The Advanced Users were not distinguishable from the Instrumental Users in frequency of PC gaming. Both groups were significantly more frequent than the others on PC games. The Offline Gamers were less frequent on this task, but significantly more frequent than the Sporadic Users. For 
TV games and Gameboy play, the pattern changes. In these tasks, the Advanced Users and Offline Gamers were indistinguishable. The Instrumental Users did not play with PC games as much, but did so significantly more than the Sporadic Users.

There were more boys than girls represented in the Advanced and Gamer topologies, while the Instrumental Users were as likely to be girls as boys. The sporadic users were mostly girls, confirming previous findings showing that girls tend to choose new media less frequently than boys do. As Table 2 shows, there is an effect of age ( $x 2=257.820$, $\mathrm{p}<.001$, eta $=.467)$. This effect is related to the Offline Gamers and Sporadic Users, where the percentage goes down with age, while the percentage of Instrumental Users increases within the age cohort. After fifth grade, the proportion of Advanced Users was stable at approximately $6 \%$.

Children in all the groups watched TV and video. It should be noted that the Sporadic Users did this at a lower frequency compared to the others, and the Instrumental Users also watched significantly less TV than both the Advanced Users and Offline Gamers.

For Newsgroup and TV chat activities, the Advanced group was significantly higher in usage than all other groups, while there were no significant differences among the other groups. The Instrumental Users were using media more for schoolwork than were the Offline Gamers and Sporadic Users, who were not significantly distinguishable.

Pertaining to more ordinary Internet tasks such as reading e-mail, surfing and downloading music, both the Offline Gamers and Sporadic Users scored low and significantly lower than the other groups. The Instrumental Users were active in these kinds of tasks, although significantly less active than the Advanced Users.

\section{Ease of Access to New Media}

The second question we asked was why children chose a particular use of new media. Here we wanted to see how accessibility influenced the children's choices. As Table 3 shows, this relationship per se does not provide an explanation for the style of use chosen by the children.

Table 3. Access to Technology at Home in Percentage for the User Groups (\%)

\begin{tabular}{|c|c|c|c|c|c|c|c|c|c|c|}
\hline & \multicolumn{5}{|c|}{ At home } & & \multicolumn{4}{|c|}{ In own room } \\
\hline & Video & $\mathrm{PC}$ & $\begin{array}{l}\text { Internet } \\
\text { Access }\end{array}$ & $\begin{array}{c}\text { Game } \\
\text { boy }\end{array}$ & $\begin{array}{l}\text { TV } \\
\text { game }\end{array}$ & TV & Video & PC & $\begin{array}{l}\text { Internet } \\
\text { Access }\end{array}$ & $\begin{array}{l}\text { TV } \\
\text { game }\end{array}$ \\
\hline Advanced Users & 98 & 94 & 91 & 73 & 89 & 53 & 34 & 46 & 25 & 49 \\
\hline Offline Gamers & 97 & 93 & 80 & 85 & 86 & 39 & 25 & 29 & 9 & 33 \\
\hline Instrumental Users & 96 & 99 & 93 & 68 & 68 & 38 & 22 & 37 & 21 & 26 \\
\hline Sporadic Users & 95 & 92 & 83 & 46 & 48 & 20 & 12 & 18 & 7 & 9 \\
\hline
\end{tabular}

For instance, there was no significant difference among the various groups regarding access to TV or video at home, PC at home or Internet access at home. There was however a significant difference regarding Gameboy $(\mathrm{x} 2=105.698, \mathrm{p}<.001$, eta $=.315)$ and TV games $(x 2=106.088, \mathrm{p}<.001$, eta $=.313)$ across the groups, with a lower percentage for the Sporadic Users and Instrumental Users. The Offline Gamers had the highest percentage of console game access, thus indicating that access plays a role in usage. Because the sporadic users have access to the different technologies, other factors necessarily affect their choices. 
A stronger claim was that access in one's own bedroom would facilitate use. As shown in Table 3, the picture is clearer here and indicates that very private access to new media plays a role. There were significant differences between the groups regarding TV in their own room $(\mathrm{x} 2=43.303, \mathrm{p}<.001$, eta $=.201)$, video in their own room $(\mathrm{x} 2=25.959, \mathrm{p}<$ .001 , eta $=.156), \mathrm{PC}(\mathrm{x} 2=41.075, \mathrm{p}<.001$, eta $=.19)$, Internet access $(\mathrm{x} 2=37.32, \mathrm{p}<$ .001 , eta $=.188)$, and TV games in their own room $(x 2=73.065, \mathrm{p}<.001$, eta $=.261)$. This indicates that the more new media access is individualized and part of the bedroom culture, the more it influences choices.

\section{Displacement}

The third question we asked was whether extensive new-media-based activities would displace other leisure activities such as reading a book or playing with others. To give an indication of displacement, a partial correlation model was used with gender and age partialized out. As Table 4 shows, the general picture is that there is little sign of substitution. The correlations are small, and few are negative.

Table 4. Partial Correlation between Estimated Total Time Spent Gaming with New Media (PC, Video and game consoles), Watching TV and Leisure Time Activities

\begin{tabular}{|c|c|c|c|c|c|c|}
\hline & $\begin{array}{c}\text { New } \\
\text { media }\end{array}$ & $\begin{array}{c}\text { Watch } \\
\text { Tv }\end{array}$ & $\begin{array}{c}\text { Advanced } \\
\text { Users }\end{array}$ & $\begin{array}{l}\text { Offline } \\
\text { Gamers }\end{array}$ & $\begin{array}{c}\text { Instrumental } \\
\text { Users }\end{array}$ & $\begin{array}{c}\text { Sporadic } \\
\text { Users }\end{array}$ \\
\hline Be with friends outdoors & .02 & $.07^{\star}$ & .20 & -.06 & .00 & .09 \\
\hline Organized sports activities & $-.14^{\star *}$ & -.03 & $-.27^{\star \star}$ & $-.22 *$ & -.08 & -.09 \\
\hline Organized music activities & -.04 & -.05 & -.01 & -.07 & -.07 & .01 \\
\hline Meetings in scouts and similar & .00 & .06 & .14 & .00 & .01 & -.01 \\
\hline Play ball outdoors & $.07^{*}$ & $.12^{\star \star}$ & $.25^{*}$ & -.01 & .07 & $.17^{\star}$ \\
\hline Be with friends indoors & $.13^{\star \star \star}$ & -.08 & $.38^{* \star}$ & $.14^{\star}$ & .10 & $.19^{\star \star}$ \\
\hline Spend time with family & .04 & .01 & .06 & .04 & .04 & .02 \\
\hline Playing inside alone & $.20^{\star \star \star}$ & $.08^{*}$ & .06 & $.30^{\star \star \star}$ & $.26^{\star \star \star}$ & .08 \\
\hline Read books or cartoons & $.10^{\star \star \star}$ & $-.06^{*}$ & .13 & .08 & $.18^{\star \star \star}$ & .08 \\
\hline Create things, paint or draw & .03 & $-.13^{\star \star}$ & .26 & .05 & -.01 & .00 \\
\hline
\end{tabular}

Note: ${ }^{*} \mathrm{p}<.05,{ }^{* *} \mathrm{p}<.01,{ }^{* * *} \mathrm{p}<.001$. Gender and age were partialized out.

For reading and creative indoor activities, there are small negative correlations with time spent on watching TV. This is in accordance with several studies that have discussed the impact of TV watching. As reported by other studies (Subrahmanyam et al. 2000), we find positive correlations between TV- and computer-based activities $(r=.26, p<$ $.001)$. This correlation was significant for Gamers $(r=.2, p<.001)$ and Instrumental Users $(\mathrm{r}=.3, \mathrm{p}<.001)$, but not for Advanced and Low Users.

Only for participation in organized sports activities did we find some indications of displacement. This is particularly related to the Advanced Users and Offline Gamers. For other IT-based media usage and leisure activities, the correlations are very low. If anything, there are some positive relationships between time spent with new media and activities like hanging out with friends and playing ball outdoors. For the Instrumental Users and Low Users, we find a correlation between time spent on media and impulsive play activity such as playing football with friends. For the Advanced Gamers and Low Users, we find a positive correlation between being indoors with friends either at home or at other children's homes. For the Gamers and Instrumental Users, this also correlates 
with being alone inside. Interestingly, there is a positive overall correlation between media activities and reading, which is significant for Instrumental Users.

\section{Discussion}

We were able to identify four distinct user types: Advanced Users, Offline Gamers, Instrumental Users and Low Users. It is important to note that these user types are characterized by a general activity pattern involving several media rather than usage of just one single medium. Furthermore, these user types also reflect both the amount of time spent and the type of activity performed. For example, Advanced Users do not necessarily use new media a great deal more than other user groups, they just choose different and more advanced activities.

The four user types identified in this study are in many ways quite similar to those found by Johnsson-Smaragdi (2001) as well as to those from Roberts and Foehr (2004). Our Advanced Users and Offline Gamers resemble the enthusiasts in the Roberts and Foehr study. In the Johnsson-Smaragdi-Study, one type that resembles our two mentioned above is identified as a "PC and games specialist". Neither of the other studies was able to differentiate between game-focused users and advanced users. The primary reason for this is probably that we asked the children for a wider range of activities with media and therefore were able to characterize them based on a more elaborated range of media usage. Roberts and Foehr (2004), for instance, based their cluster model on 6 questions, while we used 20 activity-oriented questions. Further, we only studied children under the age of 13 , while Roberts and Foehr made a typology covering media use by youth up to the age of 18. However, there has been a great need for research on the younger age group, because few studies have included children under the age of 13, as stated in the introduction.

In addition, we did not identify any particular user type mainly focused on print media. Because we wanted to test for the possible displacement of reading by extended use of new media, we did not include reading books in our pattern model as in the European Johnson-Smaragdi study. We can therefore not rule out the possibility of the existence of a more traditional media user group in our population.

The subgroups "television and games" and "screen entertainment fans" in the Johnson-Smaragdi-study (2001) resemble what we have called Offline Gamers.

All three studies find a type called low users who are indifferent to new media technologies. In the Johnson-Smaragdi study, "Low Media Users" were the largest group and were characterized by spending little time with media technologies. In the Roberts and Foehr (2004) study, this type was divided into a small group called "Media Lite", who had little access to media, and an "Indifferent" type, who lived in a rich media environment. Both groups represented approximately $20 \%$ of the population each. We also found a "Low User" type that comprised $30 \%$ of the children. However, this user group did use new media technologies to some extent, as opposed to the European study in which this group used media to a low extent.

The Low Users are an interesting group because they illustrate the fact that personal choice is an important factor in a media-saturated society. Some children choose not to use new media as much as others, even if they have access. Children are not passive absorbers of the media that are available, but instead choose what to do with them based on their preferences and interests. Generally speaking, our findings indicate the need to 
go beyond the media technology itself and to look more closely at the actual activities children want to engage in with new media.

Some key variables hint at why children end up developing a particular pattern of media usage. As has been pointed out by many studies, age and gender are important. Younger children use new media less and spend more time playing, while older children use a wider range of media technologies and spend more time with them. Girls are represented more in the Low User type, and boys more in the advanced and gaming groups. If game-playing activities are the starting point for developing the skills needed to master media technologies (e.g., Heim et al. 2007), a lack of access to games in early childhood, which is common in many girls, may explain some of the gender differences observed in the literature.

The gender differences do not present a completely divided image, however. As many boys as girls are Instrumental Users and a substantial proportion of the girls (33\%) are Advanced Users. Our study shows that girls use new media to a large extent, although in different ways than boys. This may indicate that new media produced after 2000 offer more activities that are relevant for girls than the pre-2000 literature indicates, which hopefully represents a start on closing the gender gap in regard to media use.

First of all, access to the media is an important factor, but we would argue that this is becoming less and less important as society becomes more technology-saturated. Nearly all the children in our sample had access to TV, a PC and a game console at home. What is more important seems to be to what extent media technologies enter the children's private zone: their bedroom. For example, the Low Users had as much access to new media (PC and Internet) in the household as did the other user types, but few had new media in their own rooms. This is in accordance with the findings of Roberts, Foehr and Rideout (2005), which showed that more and more children are exposed to media technologies in their bedrooms. Both the Advanced Users and Offline Gamers had access to new media in their bedrooms.

There are, however, some problems with the approach we have chosen. The items chosen to be included in the model are of course crucial, as can be seen from the three different studies discussed here. The model is as representative as the items chosen. Even in our study, we would have liked to have included more items related to communication and social activities, as well as more items related to motivation in the choice of medium activity. In addition, the criteria for how many clusters to include are not unambiguous. We chose to use the best BIC fit, but this is not a finite criterion. Because there is no unified model or gold standard for identifying user typology, more research is needed to establish a solid consensus on the number and types of usage patterns to expect.

The transition to and the boundary between one media user type and another may be fluid, thus we can expect to find combinations of different user types. The activityoriented cluster approach does not mirror an absolute typology of children's media use; rather, it reflects a more holistic approach to media use versus a single-media technology approach.

\section{Displacement}

There were little or no indications of social displacement in our material. For only two activities and two of the user types did we find small but significant negative cor- 
relations associated with new media activities. Interestingly, the tendency was for the Advanced Users to engage less in organized sports activities, whereas they spent more time playing with friends indoors. It is possible that the Advanced Users represent an out-culture group that is less a part of the organized conventional youth society and more into socializing around new media activities. This is in contrast to the Offline Gamers, who also engage in fewer sports activities, but spend more time inside alone. It should be noted that partial correlations say nothing about the causal relations between the variables. Based on these findings, we cannot conclude that participating less in sports leads to more advanced computer activities or that more advanced media usage leads to less sports activity. In addition, we used a rather rough measure of time spent with the different activities. As such, we could not estimate the number of hours per day spent with different activities; as a result, our conclusions should be treated with caution. Bearing this in mind, we did not find any clear indications of social displacement as postulated by the classic displacement hypothesis. Instead, our findings are more in accordance with the "more is more" hypothesis, implying that more active children perform many activities and more of them in parallel. This may indicate that children include new media in their social life instead of displacing social activities, thus providing a picture of active media users who are active children as opposed to loners who spend little time on other activities. As predicted by "more is more", children are incorporating new media technologies into their social lives without being less socially active.

\section{Conclusion}

In the present study, we found that younger children are making different choices in regard to new media activities. They specialize in certain areas such as gaming, making use of new media for learning and school or play. We identified four distinct user types: 1) Low Users, 2) Offline Gamers, 3) Instrumental Users and 4) Advanced Users, which creates a detailed and precise understanding of children's differentiated use.

We also confirmed the findings of Roberts, Foehr and Rideout (2005), which show that it is not general access to media, but accessibility in the very private zone that predicts the choice of media usage.

There is no evidence in our material that typical intense users of new media participate less than other children in social activities, with the exception of organized sports activities. On the contrary, we found that media active children spent more time with friends than others did. They even tended to read more and play more outdoors with friends, supporting the "more is more" hypothesis. Our findings point towards the complexity of understanding children's integration of media in their daily lives.

Critics might say that our data are old because they were collected in 2002 . However the new new media landscape in Norway was established in 2002, and included most of the technologies we see today (2009). A longitudinal study from 2003-2008 by the Norwegian Media Authority shows only a modest change in the usage of new media among children below 13 years of age (Lindbøl 2008). If anything, the time spent on new media technology has decreased somewhat since 2003, even though more children use the technology. The only exceptions to this pattern are mobile-phone-based activities, which have increased in recent years. However, new online services such as YouTube, 
which is not covered in this follow-up study, may have changed online activities by making them more audiovisual in nature.

More longitudinal research should be initiated to better understand how usage patterns develop and change over time as society becomes more media saturated. The differentiation of choice is crucial, and new sub-types of child media users will probably emerge as a consequence of this increase in media user opportunities. Therefore, future research should include more detailed analyses of usage patterns and of how younger children are influenced by and motivated to choose among different media activities.

\section{References}

Anderson, D.R. \& Hanson, K.G. (2009) 'Children, Media and Methodology', American Behavioural Scientist, $52,8,1204-1219$.

Buckman, D.D. \& Funk, J. B. (1996) 'Video and Computer Games in the 90s: Children's Time and Game Preferences', Children Today, 24, 12-15.

Beentjes, J., Koolstra, C. M., Marseille, N., \& van der Voort, T.H.A. (2001) 'Children's Use of Different Media: For How Long and Why?’ In: S. Livingstone \& M. Bovill, (eds.) Children and Their Changing Media Environment: An European Comparative Study. Hillsdale, NJ: Lawrence Erlbaum, 85-113.

Chiu, T., Fang, D., Chen, J., Wang, Y., \& Jeris, C. (2001) 'A Robust and Scalable Clustering Algorithm for Mixed Type Attributes in Large Database Environment', In: D. Lee, M. Schkolnick, F. Provost \& R. Srikant (eds.) Proceeding of the Seventh ACK SIGKDD International Conference on Knowledge Discovery and Data Mining. NY: ACM Press, 263-268.

Drotner, K. (2001) Media for the Future: Children, Youth and the New Media Landscape. [Medier for fremtiden: Børn, unge og det nye medielandskab]. København: Høst \& Søn.

Egea, J. M.O., Menéndez, M.R., \& González, M.V.R. (2007) 'Diffusion and Usage Patterns of Internet Services in the European Union', Information Research, 12,2.

Heim, J., Brandtzæg, P.B., Kaare, B.H., Endestad, T., \& Torgersen, L. (2007) Children's Usage of Media Technologies and Psychosocial Factors', New Media \& Society, 9, 425-454.

Johnsson-Smaragdi, U., \& Roe, K. (1986) 'Teenagers in the New Media World: Video Recorders, Video Games and Home Computers'. Research Paper in The Sociology of Communication. University of Lund, (2).

Johnsson-Smaragdi, U. (2001) 'Media Use Styles among the Young', In: S. Livingstone, \& M. Bovill (eds.) Children and their Changing Media Environment: A European Comparative Study. Hillsdale, NJ: Lawrence Erlbaum.

Lee, W., \& Eddie, C.Y.K. (2002) 'Internet and Displacement Effect: Children's Media Use and Activities', Journal of Computer-Mediated Communication, 7, 1-18.

Livingstone, S., \& Bovill, M. (2001) Children and their Changing Media Environment: A European Comparative Study. Hillsdale, NJ: Lawrence Erlbaum.

Livingstone, S. (2003) 'Children's Use of the Internet: Reflections on the Emerging Research Agenda', New Media \& Society, 5 (2), 147-166.

Livingstone, S., \& Bovill, M. (1999) 'Young People and New Media', Report of Research Project: Children and their Changing Media Environment. London School of Economics and Political Science.

Lindbøl, S. (2008) Trygg bruk undersøkelsen; en kartlegging av 8-18 åringers bruk av digitale medier. Medietilsynet (Norwegian Media Authority) Retrieved Online 15.12.09: http://www.medietilsynet.no/ Documents/Selvbetjening/Rapporter/Trygg_bruk_2008_rapport.

Mutz, D.C, Roberts, D.F., \& van Vuuren, D.P. (1993) 'Reconsidering the Displacement Hypothesis: Television's Influence on Children's Time Use', Communication Research, 20, 51-75.

Neuman, S.B. (1991) Literacy in the Television Aage: The Myth of the TV Effect. Norwood, NJ: Ablex.

Pasquier, D., Buzzi, C., d'Haenens, L., \& Sjöberg, U. (1998) 'Family Lifestyles and Media Use Patterns An Analysis of Domestic Media among Flemish, French, Italian and Swedish Children and Teenagers', European Journal of Communication, 13, 503-519.

\section{* Acknowledgements}

The study described here, which forms part of the research project "A digital childhood" - www. sintef.no/digitalbarndom - was funded by the Research Council of Norway: Welfare Research Programme, 2002-2004. 
Rideout, V.J., Foehr, U.G., Roberts, D.F., \& Brodie, M. (1999) Kids and Media@ the New Millennium. Executive Summary. Menlo Park, CA: Kaiser Family Foundation.

Rice, R.E. (1984) The New Media: Communication, Research and Technology. Beverly Hills, CA: Sage.

Roberts, D.F., Foehr, U.G., Rideout, V.J., \& Brodie, M. (1999) Kids and Media@ the New Millennium. Menlo Park, CA: Kaiser Family Foundation.

Roberts, D.F., Foehr, U.G., \& Rideout, V. (2005) Generation M: Media in the Lives of 8-18 Year-Olds. Menlo Park, CA: Kaiser Family Foundation.

Roberts, D.F, \& Foehr, U.G. (2004) Kids and Media in America. Cambridge University Press. Cambridge, USA.Roberts, D. F., Henriksen, L., \& Foehr, U.G., 2004. Adolescents and Media. In: R.M. Lerner \& L. Steinberg (eds.) Handbook of Adolescent Psychology. $2^{\text {nd }}$ ed. Chichester, England: Wiley, 487-521.

Rogers, E. M. (2003) Diffusion of Innovations. $5^{\text {th }}$ ed. New York: The Free Press.

Shih, C., \& Venkatesh, A. (2004) 'Beyond Adoption: Development and Application of a Use-diffusion model', Journal of Marketing, 68, 59-72.

Subrahmanyam, K., Kraut, R.E., Greenfield, P.M., \& Gross, E.F. (2000) 'The Impact of Home Computer Use on Children's Activities and Development', Children and Computer Technology, 10, 123-144.

Staksrud, E., Livingstone, S., \& Haddon, L. (2007) 'What do We Know about Children's Use of Online Technologies? A report on data availability and research gaps in Europe [short version]', EU kids online deliverable D1.1 data availability for the EC Safer Internet Plus programme, EU kids online. London, UK.

Tapscott, D. (1998) Growing up Digital: The Rise of the Net Generation. New York: McGraw-Hill.

Wartella, E., O’Keefe, B., \& Scantlin, R. (2000) 'Children and Interactive Media. A Compendium of Current Research and Directions for the Future', A report to the Markle Foundation. Markle Foundation. Available online 4 March 2003: http://www.markle.org/news/digital_kids.pdf

Wright, J.C., Huston, A.C., Vandewater, E.A., Bickham, D.S., Scantlin, R.M., \& Kotler, et al. (2001) 'American Children's Use of Electronic Media in 1997: A National Survey', Journal of Applied Developmental Psychology, 22, 31-47.

TOR ENDESTAD, Dr. Psychol., Associate Professor, Department of Psychology, University of Oslo, tor.endestad@psykologi.uio.no

JAN HEIM, Chief Scientist, SINTEF Information and Communication Technology (ICT), Oslo

BIRGIT KAARE, Dr.philos., Professor, Department of Media and Communication, University of Oslo

LEILA TORGERSEN, Dr.psychol., Researcher, Norwegian Institute of Public Health, Oslo

PETTER BAE BRANDTZÆG, Scholar, SINTEF Information and Communication Technology (ICT), Oslo 